\title{
Quercetin, a potent suppressor of NF-кB and Smad activation in osteoblasts
}

\author{
MASAYOSHI YAMAGUCHI $^{2 *}$ and M. NEALE WEITZMANN ${ }^{1-3^{*}}$ \\ ${ }^{1}$ Atlanta Department of Veterans Affairs Medical Center, Decatur, GA 30033; ${ }^{2}$ Division of Endocrinology, Metabolism \\ and Lipids, Department of Medicine and ${ }^{3}$ Winship Cancer Institute, Emory University, Atlanta, GA 30322, USA
}

Received April 14, 2011; Accepted May 6, 2011

DOI: $10.3892 / \mathrm{ijmm} .2011 .749$

\begin{abstract}
Osteoclasts, the bone resorbing cells of the body, form when osteoclast precursors are exposed to the key osteoclastogenic cytokine receptor activator of $\mathrm{NF}-\kappa \mathrm{B}$ ligand (RANKL), a process requiring induction of $N F-\kappa B$ signaling. Quercetin is a ubiquitous plant-derived flavonoid with well documented antiinflammatory properties, in part, a consequence of its capacity to downmodulate the $\mathrm{NF}-\kappa \mathrm{B}$ signal transduction pathway. Consistent with this mechanism of action quercetin is reported to suppress osteoclastogenesis in vitro and prevent bone loss in ovariectomized mice in vivo. By contrast, the effect of quercetin on osteoblasts, the cells responsible for bone formation, is contradictory with conflicting reports of inhibition as well as stimulation. Given our previous reports that $N F-\kappa B$ antagonists promote osteoblast differentiation and activity, we compared the effects of quercetin on osteoclast and osteoblast differentiation and on $\mathrm{NF}-\kappa \mathrm{B}$ signal transduction in vitro. As expected, quercetin potently suppressed osteoclastogenesis and $\mathrm{NF}-\kappa \mathrm{B}$ activation induced by RANKL in osteoclast precursors. However, the same doses of quercetin had no effect on osteoblast mineralization, and failed to significantly alleviate the inhibitory effect of $\mathrm{NF}-\kappa \mathrm{B}$-induced by $\mathrm{TNF} \alpha$, even though quercetin potently suppressed $N F-\kappa B$ activation in these cells. This apparent contradiction was explained by the fact that addition to its anti-NF- $\kappa \mathrm{B}$ activity, quercetin also potently antagonized both TGF $\beta$ and BMP-2-induced Smad activation in osteoblast precursors. Taken together our data suggest that multiple competing actions of quercetin mediate both stimulatory and inhibitory actions on osteoblasts with the final physiological effect likely a function of the net balance between these stimulatory and inhibitory effects.
\end{abstract}

Correspondence to: Dr M. Neale Weitzmann, 101 Woodruff Circle, 1305 WMRB, Atlanta, GA 30322, USA

E-mail: mweitzm@emory.edu

Dr Masayoshi Yamaguchi, 101 Woodruff Circle, 1329 WMRB, Atlanta, GA 30322, USA

E-mail: yamamasa1155@yahoo.co.jp

*Contributed equally

Key words: quercetin, NF-кB, osteoblast, osteoporosis, osteoclast

\section{Introduction}

Many naturally occurring nutritional factors and chemicals isolated from plants are now under investigation for their medicinal properties. The flavonoid quercetin is one such agent and has been found to possess potent anti-inflammatory effects

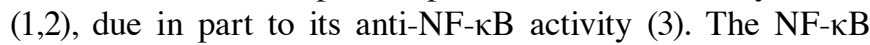
signal transduction pathway is synonymous with inflammation and mediates the effect of multiple inflammatory cytokines including the receptor activator of NF- $\mathrm{KB}$ ligand (RANKL) and TNF $\alpha$, two cytokines that have potent effects on the skeleton. Skeletal deterioration is common in inflammatory states including rheumatoid arthritis and periodontitis and in postmenopausal osteoporosis where estrogen deficiency leads to up-regulation in TNFa and RANKL (4).

At the cellular level osteoclasts, the cells that degrade (resorb) bone are derived from precursors of the monocytic lineage that differentiate into mature osteoclasts under the influence of the key osteoclastogenic cytokine RANKL. TNF $\alpha$ synergizes with RANKL at the level of signal transduction to amplify its osteoclastogenic activity. NF- $\mathrm{KB}$ is a major signal transduction pathway for both cytokines and consequently $\mathrm{NF}-\mathrm{\kappa B}$ activation is necessary to generate osteoclasts and to regulate their function (5-8). Consequently, we have demonstrated that a pharmacological antagonist to NF- $\mathrm{kB}$ inhibits osteoclastic bone loss in ovariectomized mice in vivo (9) and that natural NF- $\mathrm{\kappa B}$ antagonists including vitamin K2 (10) and $17 \beta$-estradiol (11) suppress osteoclastogenesis in vitro. NF- $\mathrm{KB}$ antagonism has also been shown to ameliorate bone degradation in an animal model of rheumatoid arthritis (12).

Studies have reported that quercetin antagonizes bone resorption in femoral organ cultures (13) and in osteoclast differentiation and/or activation assays in vitro $(14,15)$ by a mechanism that involves suppression of NF- $\mathrm{KB}$ and AP-1 (16). Interestingly, a quercetin-like varient, quercetin-6-C- $\beta$-D-glucopyranoside isolated from Ulmus wallichiana planchon has been demonstrated to possess enhanced anti-osteoclastogenic activity and to mitigate ovariectomy-induced bone loss in rats (17).

In contrast to osteoclasts, osteoblasts, the cells that build and regenerate bone are potently inhibited by $\mathrm{TNF} \alpha$ (18). Furthermore, we recently demonstrated that mice deficient in $\mathrm{TNF} \alpha$ or its type I receptor achieve a significantly higher bone mineral density as a consequence of elevated bone formation in vivo (19). We further demonstrated that pharmacological 
antagonists of NF- $\mathrm{\kappa B}$ activation promote osteoblast differentiation and mineralization in vitro $(10,19,20)$. Recently our studies were ratified in vivo by a report of time- and stage-specific inhibition of NF- $\mathrm{kB}$ activation in differentiated osteoblasts leading to increased trabecular bone mass and bone mineral density (21). Additional studies have reported increased bone formation and amelioration of osteopenia in ovariectomized mice treated with pharmacological NF- $\mathrm{BB}$ inhibitors (22). Also consistent with these data TNF $\alpha$ antagonists have been shown to promote bone regeneration in a fracture repair model (23).

The action of quercetin on osteoblasts and bone formation however is contentious. Quercetin has been reported to inhibit the proliferation, differentiation, and mineralization of osteoblasts in vitro (24) and promote TNF $\alpha$-induced inhibition (25) and apoptosis $(25,26)$. Other studies however, report increased alkaline phosphatase (an early osteoblast differentiation marker) levels in human MG-63 osteoblast cells (27) and stimulatory effects on bone formation in rat organ cultures ex vivo (13).

In this study we compared the effects of quercetin on osteoclastogenesis and on osteoblast differentiation. Our data reveal that despite potent suppression by quercetin of TNF $\alpha$ induced NF- $\mathrm{KB}$ in osteoblasts, the overall effects of quercetin on osteoblast differentiation were not stimulatory, a possible consequence of other non-specific actions of quercetin on other pathways including direct suppressive actions of quercetin on Smad signal transduction.

\section{Materials and methods}

Materials. $\alpha$-minimal essential medium ( $\alpha$-MEM) and antibiotics (penicillin and streptomycin) were purchased from Invitrogen Corp. (Carlsbad, CA). Fetal bovine serum (FBS) was from Hyclone. RANKL, TNF $\alpha$, TGF $\beta$ and BMP-2 were from R\&D Systems (Minneapolis, MN). Quercetin, anti-polyhistidine antibody, leukocyte acid phosphatase kits and all other reagents were purchased from the Sigma-Aldrich Chemical Corporation, (St. Louis, MO) unless otherwise specified.

Cell culture. The preosteoblastic cell line MC3T3-E1, clone 14 (MC3T3) was purchased from the American Type Culture Collection (Manassas, VA) and cultured as previously described $(19,28)$.

Osteoclastogenesis assays and TRAP staining. RAW264.7 cells cultured for 6 days with RANKL (30 ng/ml) pre-incubated for 10 min with crosslinking anti-poly-histidine antibody $(2.5 \mu \mathrm{g} / \mathrm{ml})$ to induce osteoclast formation, in the presence or absence of quercetin at the indicated dosage. Cells were fixed and stained for tartrate resistant acid phosphatase (TRAP) activity using a leukocyte acid phosphatase kit. $\mathrm{TRAP}^{+}$cells with three or more nuclei were defined as osteoclasts and were quantitated under light microscopy and 5 wells/group were averaged.

Osteoblast differentiation assays and Alizarin Red-S staining. Mineralization assays using MC3T3 cells were performed in the presence or absence of quercetin at the indicated dosage, with calcium visualization using Alizarin Red-S. Experimental procedures were performed exactly as described in our previous studies $(10,19,29)$.

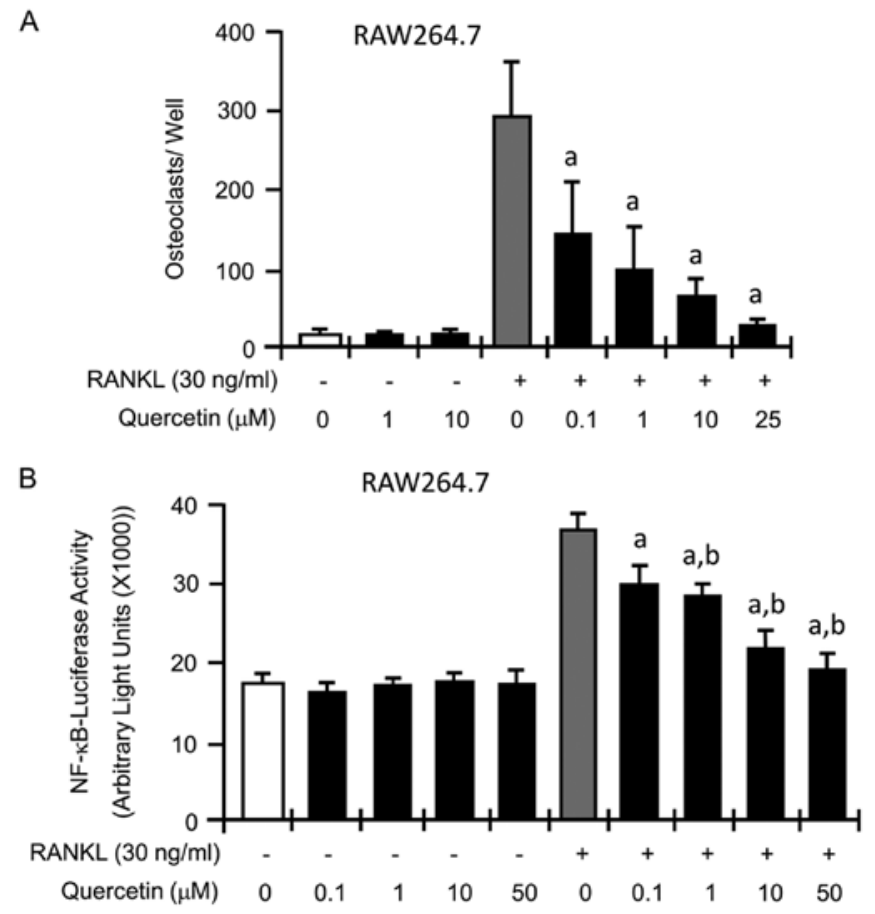

Figure 1. Quercetin suppresses osteoclast differentiation and RANKL-induced $\mathrm{NF}-\kappa \mathrm{B}$ activation in vitro. (A) RAW264.7 cells were treated with RANKL $(30 \mathrm{ng} / \mathrm{ml})$ in the presence or absence of a dose range of quercetin $(0,0.1,1$, 10 or $25 \mu \mathrm{M}$ ) for 7 days and TRAP stained. TRAP ${ }^{+}$multinucleated cells ( 3 or more nuclei) were quantitated and averaged for 5 independent wells for each data point. ${ }^{\text {a }}<<0.001$ relative to RANKL only (grey bar). (B) RAW264.7 cells were transfected with $\mathrm{NF}-\kappa \mathrm{B}-\mathrm{Luc}$ reporter and $\mathrm{NF}-\kappa \mathrm{B}$ activation induced by stimulation with RANKL (30 ng/ml), in the presence or absence of a dose range of quercetin $(0,0.1,1,10$ or $50 \mu \mathrm{M})$. Data represent the mean $\pm \mathrm{SD}$ of 5 replicate samples. All data are representative of 2 independent experiments. ${ }^{\mathrm{a}} \mathrm{P}<0.05$ and ${ }^{\mathrm{b}} \mathrm{P}<0.001$ vs. RANKL only (grey bar).

$N F-\kappa B$ constructs and luciferase assays. NF- $\kappa \mathrm{B}$ and Smad activation was assessed in MC3T3 or RAW264.7 cells using luciferase reported assays using the NF- $\mathrm{\kappa B}$ responsive reporter pNF- $\kappa B-L u c$ (BD Biosciences) or pGL3-Smad, responsive to all receptor-regulated (R)-Smads as previously described $(10,19)$. Some cultures were treated with quercetin at the indicated dosages.

Statistical analysis. Statistical significance was determined using the GraphPad InStat version 3 for Windows XP (GraphPad Software, Inc., La Jolla, CA). Multiple comparisons were performed by one-way analysis of variance (ANOVA) with the Tukey-Kramer multiple comparisons post-test for parametric data. The Gaussian distribution was assessed using the Kolmogorov and Smirnov test. A P-value $<0.05$ was considered statistically significant.

\section{Results}

Quercetin potently suppresses RANKL-induced osteoclast formation. The effect of quercetin on osteoclast formation was examined using RAW264.7 cells which differentiate into mature multinucleated osteoclasts when treated with RANKL. Quercetin potently and dose-dependently inhibited RANKL-induced osteoclastogenesis in the examined range of concentrations $(0.1,1,10$, and $25 \mu \mathrm{M})$ (Fig. 1A). 
A

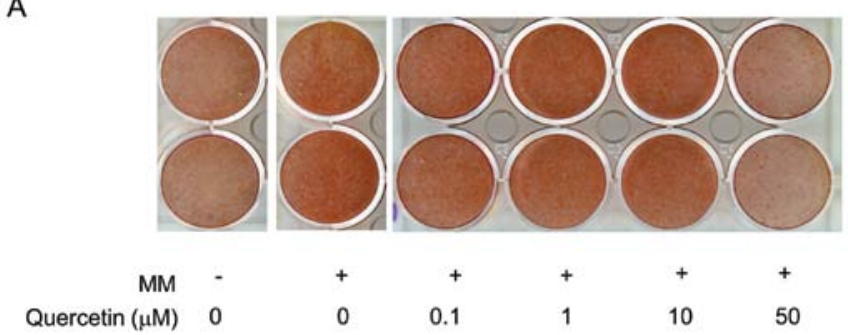

B
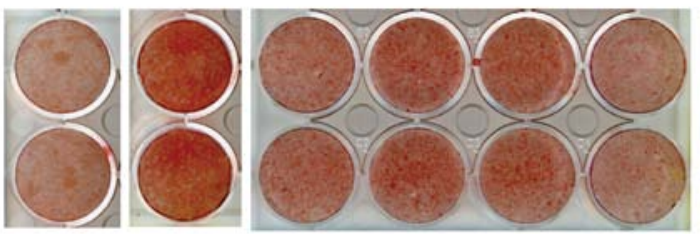

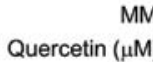
$\operatorname{TNF} \alpha(5 \mathrm{ng} / \mathrm{ml})$

$+$

0

0
0

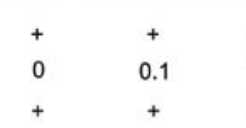

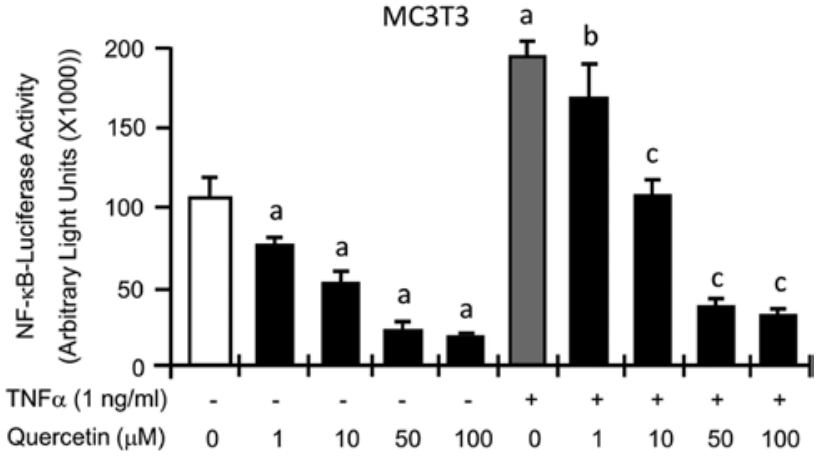

Figure 3. Quercetin suppresses basal and TNF $\alpha$-induced NF-кB activation in vitro. MC3T3 cells were transfected with the NF- $\mathrm{kB}-\mathrm{Luc}$ reporter and NF- $\kappa \mathrm{B}$ activation was examined under basal or TNF $\alpha(1 \mathrm{ng} / \mathrm{ml})$-induced conditions, in the presence or absence of a dose range of quercetin $(0,1$, 1050 or $100 \mu \mathrm{M})$. Data represent the mean \pm SD of 5 replicate samples. All data are representative of 2 independent experiments. ${ }^{a} \mathrm{P}<0.001$ relative to the untreated control (white bar). ${ }^{b} \mathrm{P}<0.01,{ }^{\mathrm{c}} \mathrm{P}<0.001$ relative to the $\mathrm{TNF} \alpha$ only treatment group (grey bar).

TNF $\alpha$ 's inhibitory action, but by $10 \mu \mathrm{M}$ slightly exacerbated the inhibitory effect of TNF $\alpha$. ence (+) or absence (-) of mineralizing medium (MM) and with a dose range of quercetin $(0,0.1,1,10$ or $50 \mu \mathrm{M})$. The effects of quercetin on mineralization were assessed under: (A) basal conditions or (B) in the presence or absence of TNF $\alpha(5 \mathrm{ng} / \mathrm{ml})$. Cells were stained for calcium deposition with Alizarin Red-S. For each experiment all wells were performed in duplicate and are derived from the same plate but were digitally rearranged for clarity. A white line is left between wells to indicate this fact. The data represent the mean \pm SD of 5 replicate samples and are representative of 3 independent experiments.

To assess the effect of quercetin on NF- $\kappa \mathrm{B}$ activation in osteoclasts we transfected an $\mathrm{NF}-\kappa \mathrm{B}$ luciferase reporter into RAW264.7 cells and measured luciferase activity $18 \mathrm{~h}$ later. Consistent with the osteoclastogenesis assays quercetin antagonized RANKL-induced NF- $\kappa \mathrm{B}$ activation in the dose range examined $(0.1,1,10$ and $50 \mu \mathrm{M})$ (Fig. 1B).

Quercetin has no effect on the differentiation of MC3T3 cells into mineralizing osteoblasts at a low-dose but inhibits mineralization at a high-dose. In contrast to osteoclasts in which quercetin is generally found to be inhibitory, the data for osteoblast differentiation is contradictory. Given the known inhibitory action of $\mathrm{NF}-\kappa \mathrm{B}$ on osteoblast differentiation and the anti-NF- $\kappa \mathrm{B}$ activity of quercetin it would be expected for quercetin to have a stimulatory role in osteoblasts. The effect of quercetin on in vitro osteoblast differentiation and activity was assessed by treating MC3T3 cells with quercetin at $(0.1,1,10$ or $50 \mu \mathrm{M})$ in mineralizing medium for 21 days followed by Alizarin Red-S staining for calcium deposition. The data demonstrate (Fig. 2A) that between 0.1 and $10 \mu \mathrm{M}$ quercetin had no effect on mineralization, but at $50 \mu \mathrm{M}$ had a suppressive activity on the differentiation of MC3T3 cells into mineralizing osteoblasts.

TNF $\alpha$ is a potent inhibitor of osteoblastic differentiation both in vivo and in vitro $(18,19)$ but this repression can be alleviated by NF- $\mathrm{NB}$ antagonists. We thus examined the effect of quercetin on TNF $\alpha(5 \mathrm{ng} / \mathrm{ml})$-induced osteoblast mineralization. As expected TNFa inhibited mineralization (Fig. 2B). Quercetin at 0.1 and $1 \mu \mathrm{M}$ exhibited a very weak alleviation of
Quercetin suppresses basal and TNF $\alpha$-induced $N F-\kappa B$ activity in MC3T3 cells. Because quercetin is reported to antagonize $\mathrm{NF}-\kappa \mathrm{B}$, a pathway inhibitory to osteoblast differentiation and a key mechanism of TNF $\alpha$ signaling we next investigated whether quercetin antagonizes basal and/or $\mathrm{TNF} \alpha$-induced $\mathrm{NF}-\kappa \mathrm{B}$ activation. MC3T3 cells were transiently transfected with an $\mathrm{NF}-\kappa \mathrm{B}$ luciferase reporter and we quantitated luciferase activity in the presence or absence of quercetin $18 \mathrm{~h}$ later. Quercetin potently and dose-dependently suppressed both basal and $\mathrm{TNF} \alpha$-induced $\mathrm{NF}-\kappa \mathrm{B}$ activity (Fig. 3).

Quercetin fails to alleviate the suppressive actions of TNF $\alpha$ on BMP-2- and TGF $\beta$-induced Smad activation in MC3T3 cells and directly inhibits TGF $\beta$ and BMP-2-induced Smad activation. TGF $\beta$ and BMP-2 are early and late osteoblast commitment and differentiation factors respectively, and both signal in a large measure though the Smad pathway, albeit though different R-Smads. The effect of quercetin on BMP-2-induced (Fig. 4A) and TGF $\beta$-induced (Fig. 5A) Smad activation was assessed in MC3T3 cells transfected with a Smad-luciferase reporter (19). Surprisingly, quercetin alone elicited a direct potent dose responsive (0.1 to $25 \mu \mathrm{M})$ suppression of both BMP-2-induced (Fig. 4A) and TGF $\beta$-induced (Fig. 5A) Smad activation.

We have previously shown that $\mathrm{TNF} \alpha$ suppresses osteoblast differentiation, in part, by antagonizing Smad activation by BMP-2 and TGF $\beta$. Consequently, we examined the capacity of quercetin to alleviate the suppressive action of TNF $\alpha$ on Smad induction by BMP-2 and TGF $\beta$. Quercetin failed to alleviate the suppressive action of TNFa on BMP-2-induced (Fig. 4B), or TGF $\beta$-induced (Fig. 5B) Smad-activation. In fact, quercetin significantly amplified the inhibitory effect of TNF $\alpha$ on Smad activation induced by both cytokines.

\section{Discussion}

Quercetin has been previously reported to suppress osteoclast differentiation $(13,14,16)$, in part by antagonizing the $\mathrm{NF}-\kappa \mathrm{B}$ 
A

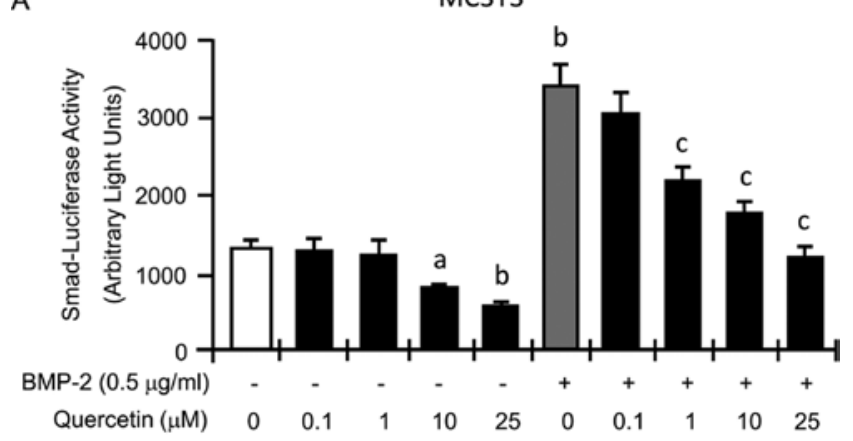

B

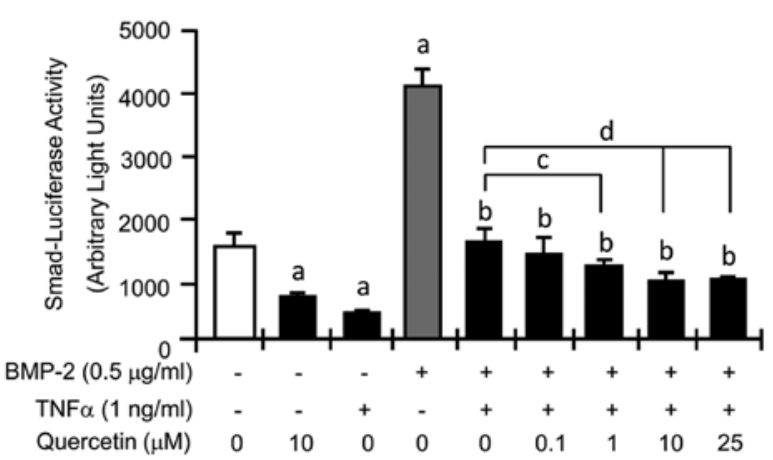

Figure 4. Effect of quercetin on BMP-2-induced Smad activation in osteoblast precursors in the presence or absence of TNF $\alpha$. MC3T3 cells were transfected with pGL3-Smad, a luciferase Smad activity reporter. (A) The effect of a dose range of quercetin $(0,0.1,1,10$ or $25 \mu \mathrm{M})$ on basal or BMP-2 $(0.5 \mu \mathrm{g} / \mathrm{ml})$-induced cells. (B) Smad activity was induced with $0.5 \mu \mathrm{g} / \mathrm{ml}$ BMP-2 and cultures treated with $1 \mathrm{ng} / \mathrm{ml} \mathrm{TNF} \alpha$, a Smad activation inhibitor, in the presence or absence of quercetin $(0,0.1,1,10$ or $25 \mu \mathrm{M})$. Smad-induced luciferase activity was quantitated for (A) and (B) $18 \mathrm{~h}$ later. ${ }^{\mathrm{a}} \mathrm{P}<0.01,{ }^{\mathrm{b}} \mathrm{P}<0.001$ relative to the untreated control (white bar). ${ }^{\mathrm{C}} \mathrm{P}<0.001$ relative to the BMP-2 treated (grey bar). The data represent mean $\pm \mathrm{SD}$ of five transfections/data point and are representative of 2 independent experiments.

activation by RANKL (16). Our data are fully consistent with these previous studies.

By contrast, the effect of quercetin on osteoblast differentiation is less clear cut with both suppression and stimulation being reported $(13,24-27,30)$. As we have previously demonstrated that a number of factors with bone anabolic activity function by antagonizing NF- $\mathrm{B}(10,11,19,20)$, we assessed the effect of quercetin on NF- $\kappa \mathrm{B}$ activation in MC3T3 osteoblast precursors. While our data indeed validate a potent suppressive effect of quercetin on TNF $\alpha$-induced $N F-\kappa B$ activation, surprisingly this did not translate into a strong bone anabolic effect. Instead quercetin displayed very weak anabolic activity at the low-dose and even a suppressive activity at high-dose, although general toxicity was not observed.

We have previously shown that TNF $\alpha$ is a potent physiological and pathological suppressor of bone formation and reduces peak bone mineral density in vivo (19). One mechanism by which $\mathrm{TNF} \alpha$ suppresses osteoblastogenesis is by antagonizing the activation of Smad signal transduction by TGF $\beta$ and BMP-2 (19), early commitment (31) and late differentiation (32) factors respectively. We have further demonstrated that NF- $\mathrm{BB}$ antagonists generally reverse the suppressive action of TNF $\alpha$ on Smad signaling $(10,19,20)$. In the case of quercetin this outcome was not found to be true and quercetin significantly added to the inhibitory action of $\mathrm{TNF} \alpha$, rather than alleviating it. Although
A

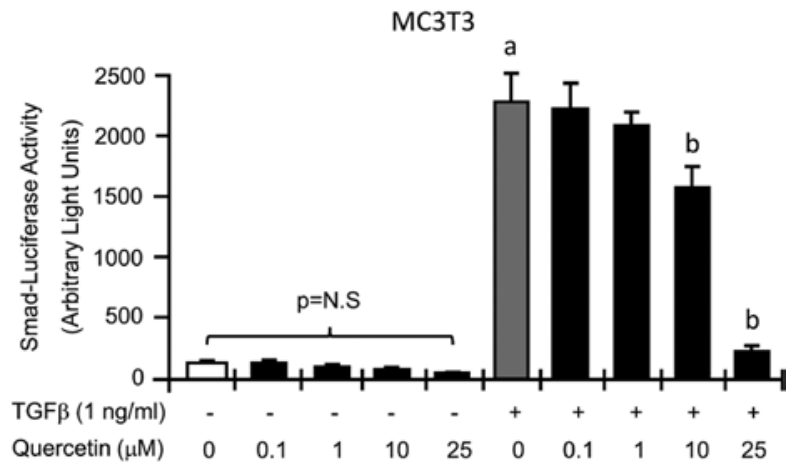

B

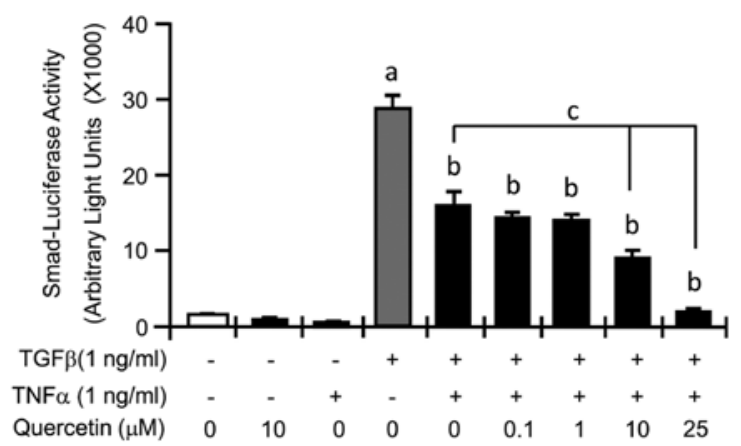

Figure 5. Effect of quercetin on TGF $\beta$-induced Smad activation in osteoblast precursors in the presence or absence of TNF $\alpha$. MC3T3 cells were transfected with pGL3-Smad, a luciferase Smad activity reporter. (A) The effect of quercetin $(0,0.1,1,10$ or $25 \mu \mathrm{M})$ on basal or TGF $\beta(1 \mathrm{ng} / \mathrm{ml})$-induced cells. (B) Smad activity was induced with TGF $\beta(1 \mathrm{ng} / \mathrm{ml})$ and cultures treated with $\mathrm{TNF} \alpha(1 \mathrm{ng} / \mathrm{ml})$, in the presence or absence of a dose range of quercetin $(0,0.1,1,10$ or $25 \mu \mathrm{M})$. Smad-induced luciferase activity was quantitated for (A) and (B) $18 \mathrm{~h}$ later. ${ }^{a} \mathrm{P}<0.001$ relative to untreated control (white bar). ${ }^{\mathrm{b}} \mathrm{P}<0.001$ relative to BMP-2 treated (grey bar). The data represent mean \pm SD of five transfections/data point and are representative of 2 independent experiments.

unexpected, our data are consistent with a previous report in which quercetin inhibited Smad activation in keloid-derived fibroblasts (33).

Taken together our data suggest the existence of complex competing actions of quercetin on osteoblast signal transduction pathways. Ultimately, the net effect of quercetin on osteoblasts in vitro and in vivo may be dose and context dependent with the prevailing concentrations of competing cytokines and growth factors in the bone marrow microenvironment determining whether the final effect is stimulatory or inhibitory to bone formation.

The specific mechanisms by which quercetin is able to modulate both NF- $\kappa \mathrm{B}$ and Smad, and potential other signaling systems remains to be determined, and may ultimately facilitate the rational design of antagonists possessing either $\mathrm{NF}-\kappa \mathrm{B}$ or Smad inhibitory actions for use as anti-inflammatory pharmaceuticals to ameliorate bone loss and other diseases associated with inflammation.

\section{Acknowledgements}

Dr M.N.W. is supported in part by the Biomedical Laboratory Research and Development Service of the VA Office of Research and Development (5I01BX000105) and in part by NIH grants NIAMS grant AR059364, AR056090 and AR053607. 


\section{References}

1. Cheng WC, Huang RY, Chiang CY, et al: Ameliorative effect of quercetin on the destruction caused by experimental periodontitis in rats. J Periodontal Res 45: 788-795, 2010.

2. Hamalainen M, Nieminen R, Vuorela P, Heinonen $M$ and Moilanen E: Anti-inflammatory effects of flavonoids: genistein, kaempferol, quercetin, and daidzein inhibit STAT-1 and NF-kappaB activations, whereas flavone, isorhamnetin, naringenin, and pelargonidin inhibit only NF-kappaB activation along with their inhibitory effect on iNOS expression and NO production in activated macrophages. Mediators Inflamm 2007: 45673, 2007.

3. Nam NH: Naturally occurring NF-kappaB inhibitors. Mini Rev Med Chem 6: 945-951, 2006

4. Weitzmann MN and Pacifici R: Estrogen deficiency and bone loss: an inflammatory tale. J Clin Invest 116: 1186-1194, 2006.

5. Iotsova V, Caamano J, Loy J, Yang Y, Lewin A and Bravo R Osteopetrosis in mice lacking NF-kappaB1 and NF-kappaB2. Nat Med 3: 1285-1289, 1997.

6. Xing L, Bushnell TP, Carlson L, et al: NF-kappaB p50 and p52 expression is not required for RANK-expressing osteoclast progenitor formation but is essential for RANK- and cytokinemediated osteoclastogenesis. J Bone Miner Res 17: 1200-1210, 2002.

7. Vaira S, Johnson T, Hirbe AC, et al: RelB is the NF-kappaB subunit downstream of NIK responsible for osteoclast differentiation. Proc Natl Acad Sci USA 105: 3897-3902, 2008.

8. Boyce BF, Yao Z and Xing L: Functions of nuclear factor kappaB in bone. Ann NY Acad Sci 1192: 367-375, 2010.

9. Strait K, Li Y, Dillehay DL and Weitzmann MN: Suppression of NF- $\mathrm{KB}$ activation blocks osteoclastic bone resorption during estrogen deficiency. Int J Mol Med 21: 521-525, 2008

10. Yamaguchi M and Weitzmann MN: Vitamin K2 stimulates osteoblastogenesis and suppresses osteoclastogenesis by suppressing NF- $\kappa$ B activation. Int J Mol Med 27: 3-14, 2011.

11. Yamaguchi M and Weitzmann MN: The estrogen $17 \beta$-estradiol and phytoestrogen genistein mediate differential effects on osteoblastic NF-אB activity. Int J Mol Med 23: 297-301, 2009.

12. Dai S, Hirayama T, Abbas S and Abu-Amer Y: The IkappaB kinase (IKK) inhibitor, NEMO-binding domain peptide, blocks osteoclastogenesis and bone erosion in inflammatory arthritis. J Biol Chem 279: 37219-37222, 2004.

13. Yamaguchi $M$, Hamamoto $R$, Uchiyama $S$ and Ishiyama $K$ Effects of flavonoid on calcium content in femoral tissue culture and parathyroid hormone-stimulated osteoclastogenesis in bone marrow culture in vitro. Mol Cell Biochem 303: 83-88, 2007.

14. Woo JT, Nakagawa H, Notoya M, et al: Quercetin suppresses bone resorption by inhibiting the differentiation and activation of osteoclasts. Biol Pharm Bull 27: 504-509, 2004.

15. Wattel A, Kamel S, Mentaverri R, et al: Potent inhibitory effect of naturally occurring flavonoids quercetin and kaempferol on in vitro osteoclastic bone resorption. Biochem Pharmacol 65: 35-42, 2003.

16. Wattel A, Kamel S, Prouillet C, et al: Flavonoid quercetin decreases osteoclastic differentiation induced by RANKL via a mechanism involving NF-kappaB and AP-1. J Cell Biochem 92: 285-295, 2004
17. Siddiqui JA, Sharan K, Swarnkar G, et al: Quercetin-6-C-betaD-glucopyranoside isolated from Ulmus wallichiana planchon is more potent than quercetin in inhibiting osteoclastogenesis and mitigating ovariectomy-induced bone loss in rats. Menopause 18: 198-207, 2011.

18. Nanes MS: Tumor necrosis factor-alpha: molecular and cellular mechanisms in skeletal pathology. Gene 321: 1-15, 2003.

19. Li Y, Li A, Strait K, Zhang H, Nanes MS and Weitzmann MN: Endogenous TNFalpha lowers maximum peak bone mass and inhibits osteoblastic smad activation, through NF-kappaB. J Bone Miner Res 22: 646-655, 2007.

20. Yamaguchi M and Weitzmann MN: The bone anabolic carotenoids p-hydroxycinnamic acid and $\beta$-cryptoxanthin antagonize $\mathrm{NF}-\kappa \mathrm{B}$ activation in MC3T3 preosteoblasts. Mol Med Rep 2: 641-644, 2009.

21. Chang J, Wang Z, Tang E, et al: Inhibition of osteoblastic bone formation by nuclear factor-kappaB. Nat Med 15: 682-689, 2009.

22. Alles N, Soysa NS, Hayashi J, et al: Suppression of NF-kappaB increases bone formation and ameliorates osteopenia in ovariectomized mice. Endocrinology 151: 4626-4634, 2010

23. Wahl EC, Aronson J, Liu L, et al: Restoration of regenerative osteoblastogenesis in aged mice: modulation of TNF. J Bone Miner Res 25: 114-123, 2010.

24. Notoya M, Tsukamoto Y, Nishimura H, et al: Quercetin, a flavonoid, inhibits the proliferation, differentiation, and mineralization of osteoblasts in vitro. Eur J Pharmacol 485: 89-96, 2004.

25. Son YO, Kook SH, Choi KC, et al: Quercetin, a bioflavonoid, accelerates TNF-alpha-induced growth inhibition and apoptosis in MC3T3-E1 osteoblastic cells. Eur J Pharmacol 529: 24-32, 2006.

26. Nam TW, Yoo CI, Kim HT, Kwon CH, Park JY and Kim YK: The flavonoid quercetin induces apoptosis and inhibits migration through a MAPK-dependent mechanism in osteoblasts. J Bone Miner Metab 26: 551-560, 2008.

27. Prouillet C, Maziere JC, Maziere C, Wattel A, Brazier M and Kamel S: Stimulatory effect of naturally occurring flavonols quercetin and kaempferol on alkaline phosphatase activity in MG-63 human osteoblasts through ERK and estrogen receptor pathway. Biochem Pharmacol 67: 1307-1313, 2004.

28. Yamaguchi M and Weitzmann MN: The bone anabolic carotenoid $\beta$-cryptoxanthin enhances transforming growth factor- $\beta 1$-induced SMAD activation in MC3T3 preosteoblasts. Int J Mol Med 24: 671-675, 2009.

29. Sugimoto $E$ and Yamaguchi M: Anabolic effect of genistein in osteoblastic MC3T3-E1 cells. Int J Mol Med 5: 515-520, 2000.

30. Siddiqui JA, Swarnkar G, Sharan K, et al: A naturally occurring rare analog of quercetin promotes peak bone mass achievement and exerts anabolic effect on osteoporotic bone. Osteoporos Int: Jan 12, 2011 (Epub ahead of print).

31. Janssens K, Ten Dijke P, Janssens S and Van Hul W: Transforming growth factor-betal to the bone. Endocr Rev 26: 743-774, 2005

32. Canalis E, Economides AN and Gazzerro E: Bone morphogenetic proteins, their antagonists, and the skeleton. Endocr Rev 24: 218-235, 2003.

33. Phan TT, Lim IJ, Chan SY, Tan EK, Lee ST and Longaker MT: Suppression of transforming growth factor beta/smad signaling in keloid-derived fibroblasts by quercetin: implications for the treatment of excessive scars. J Trauma 57: 1032-1037, 2004. 